\title{
Então Inferidor como Marca de Constituição de Subjetividade E de Instanciação de Sentidos Na Entrevista Sociolingüística*
}

\author{
(Inference então as Mark of Subjectivity Construction and \\ Meaning Actualization in Sociolinguistics Interviews)
}

Maria Alice TAVAres

(Universidade Federal do Rio Grande do Norte)

AвSTRACT: In this article we approach the labovian sociolinguistics interview as a discursive practice. Guided by the French branch of Discourse Analysis theoretical perspective, we investigate meanings which are built from the relationship between specific "places": that of the interviewer and that of the interviewee. We focus on a linguistic item in the former's discourse - então - to analyze the part played by that item on subjectivity construction process. We conclude that the interviewer, when occupying the researcher position, becomes agent of meaning actualization and meaning displacement in sociolinguistics interviews, and that então is a linguistic mark of researcher position.

KEY-WORDS: Subjectivity; Sociolinguistics interviews; Inference; Então.

Resumo: Neste estudo, abordamos a entrevista sociolingüística de linha laboviana como uma prática discursiva. Seguindo o dispositivo teórico da Análise do Discurso de linha francesa, objetivamos investigar os sentidos que são construídos pela relação entre "lugares" específicos, o de entrevistador e o de entrevistado, atentando para um elemento lingüístico do discurso do primeiro - então - para analisar o papel desse elemento nos processos de construção da subjetividade. Concluímos que o entrevistador, tomado na posição de pesquisador, torna-se agente materializador da atualização e do deslocamento de sentidos em uma entrevista sociolingüística, e que então é uma marca lingüística da posição de pesquisador.

PALAVRAS-CHAVE: Subjetividade; Entrevistas sociolingüísticas, Então inferidor.

\footnotetext{
* Agradeço ao Prof. Dr. Pedro de Souza (UFSC) pela orientação prestada no decorrer da elaboração deste artigo, que fez parte do meu processo de qualificação no Curso de Doutorado em Lingüística da Universidade Federal de Santa Catarina (UFSC), assim como pelo incentivo por sua publicação. Agradeço também aos Profs. Drs. Maria Marta Furlanetto (UNISUL) e Fábio L. Lopes da Silva (UFSC) pela leitura deste texto e valiosas sugestões.
}

D.E.L.T.A., 20:1, 2004 (77-95) 


\section{Introdução}

$\mathrm{Na}$ entrevista sociolingüística de linha laboviana, a postura de cada um dos participantes, o informante e o entrevistador, em relação a si mesmo, a seu interlocutor e aos sentidos instanciados no discurso, é vinculada a uma prática discursiva - a entrevista para a coleta de dados lingüísticos variáveis - e suas implicações. Seguindo o dispositivo teórico da Análise do Discurso de linha francesa, analisamos a relação entre a posição sujeito "entrevistador" e uma marca lingǘstica do discurso, o conector que denominamos então inferidor, buscando verificar como esse item constitui-se em marca material da interpelação do entrevistador em sujeito, no quadro de interlocução da entrevista sociolingüística. Analisamos também o jogo de mobilização de sentidos instaurado pelo processo de inferência marcado lingüisticamente por então, que incide sobre a própria constituição do sujeito.

\section{O dispositivo teórico}

A Análise do Discurso de linha francesa (doravante AD) toma como objeto de estudo o discurso, entendido como um objeto histórico que se manifesta materialmente através da língua. Ao tratar seu objeto como indissociável da história, traz à tona a natureza ideológica do discurso e da própria língua: eles existem em relação constitutiva com a sua exterioridade, isto é, relacionados à organização social humana. Portanto, não são frutos de expressão individual: o indivíduo que enuncia o discurso é tomado pela ideologia no momento em que diz. Assim como o dizer, ${ }^{1}$ o sujeito não existe em si, não é objetivo, universal, nem subjetivo, individual. Não é tido, portanto, como a origem do seu discurso, mas sim como resultan$\mathrm{do}^{2}$ da mesma fonte de que provém o dizer: a relação de constituição entre a língua e aquilo que é exterior a ela, qual seja, a historicidade.

O termo historicidade não se reporta a uma história cronológica, mas à história enquanto interpretação do mundo. A historicidade ocorre quan-

\footnotetext{
"Dizer" é aqui tomado como "discurso".

2 O discurso é algo em constituição, pois as coisas nunca estão dadas, evidentes, mas sempre em "relação a". Assim, pode-se dizê-lo como "resultando", isto é, constituindo-se. Trata-se de uma operação, um funcionamento, um “-ando”, não um “-ado”, envolvendo elementos não lingüísticos (historicidade) e lingüísticos.
} 
do os sentidos advindos da experiência humana com as formas de organização sócio-econômica se colocam como possibilidade, não como datados e acabados. Ela refere-se a tudo o que o homem construiu ao longo do tempo - formas de organização humana, instituições... - e manifesta-se no discurso através da ideologia, determinando sujeitos, sentidos, e deixando, por vezes, marcas lingüísticas bastante explícitas de sua ação. Sendo assim, $\mathrm{o}(\mathrm{s})$ sujeito(s) e o(s) sentido(s) de um discurso não são transparentes, porém opacos, devendo ser analisados levando-se em conta seus processos históricos de constituição. "O discurso pertence a um sistema de normas (...) que derivam da estrutura de uma ideologia política, correspondendo, pois, a um certo lugar no interior de uma formação social dada" (Pêcheux 1988:77). Há uma relação constitutiva - constituindo-se... - indissociável entre o dizer e suas condições de produção.

As posições que um indivíduo pode/deve ocupar no discurso são autorizadas pelas formações imaginárias, que derivam da experiência humana ao longo do tempo no contexto social, ou seja, advêm da historicidade. Constituem a imagem de um sujeito: a visão que se tem de um pai, de um filho, de um entrevistado, de um entrevistador - a imagem que o indivíduo faz de sua posição, do outro (ouvinte) e do objeto do discurso. A imagem que o indivíduo faz da posição (ou posições) que ocupa em um determinado discurso origina-se de uma formação imaginária e manifestase discursivamente por meio da materialidade lingüística, podendo haver marcas lingüísticas específicas que revelem a posição de sujeito assumida por quem diz. É o que propomos ser o caso de "então" inferidor: uma marca lingüística da construção da subjetividade na entrevista sociolingüística.

As formações imaginárias inserem-se em formações discursivas, que são conjuntos “(...) de regras anônimas, históricas, determinadas no tempo e no espaço, que definem em uma época e para uma área social, econômica, geográfica ou lingüística dada, as condições de exercício da função enunciativa" (Foucault 1969, apud Maingueneau 1993:14). As regras ou regularidades vigentes em uma formação discursiva não são fechadas, são condições de produção para um discurso, englobando todas as possibilidades de discurso, de constituição de sujeitos (através de formações imaginárias) e sentido. Aqui se faz importante sublinhar a noção de memória. Todo dizer está relacionado a uma memória, mobilizando um arquivo, isto é, mobilizando os discursos relevantes que estão disponíveis acerca de uma 
questão. Os sentidos não estão soltos, eles são mobilizáveis na memória do dizer.

As formações discursivas permitem a manifestação das formações ideológicas, a partir das quais surgem as formações imaginárias. "Para que se encontrem as regularidades de seu funcionamento, todo discurso deve ser remetido à formação discursiva que, por sua vez se define pela relação (x ou y) que tem com a formação ideológica" (Orlandi 1986:117). A experiência humana ao longo do tempo acabou por constituir certos padrões de "pensamento" - padrões ideológicos, modos de ver e dizer o mundo - que regulam o que pode ser feito/dito dentro de certos setores. Assim, podemos considerar como formação ideológica as representações ou conjuntos de valores pertinentes a setores como religião (por exemplo, uma formação ideológica católica, evangélica, etc), política/economia (formação ideológica socialista, capitalista, etc), e outras. As formações ideológicas fornecem como condições de discurso para as formações discursivas as representações necessárias para ver e dizer o mundo. A partir dessas condições discursivas históricas, as formações discursivas interpelem o indivíduo em sujeito, colocando-o em certa posição.

A constituição de um discurso envolve um processo de identificação: “(...) o sujeito se inscreve em uma formação (e não em outra) para que as suas palavras tenham sentido e isto lhe parece como "natural", como o sentido lá, transparente" (Orlandi 1996: 85). Ao ser assujeitado por certa posição de sujeito, recorrendo a determinado arquivo da memória do dizer para produzir sentidos, o indivíduo está interpretando formações ideológicas. Discursar é interpretar. No entanto, no momento mesmo em que se dá tal interpretação (o momento da constituição do discurso), ela é apagada, do que resulta o sujeito ter a ilusão de autoria do seu dizer. Quem fala, no momento em que fala, apaga a interpretação que faz daquilo que as formações ideológicas possibilitam para si enquanto discurso, via formação discursiva.

\section{A entrevista sociolingüística}

Em seus estudos sobre o processo de constituição da subjetividade que funciona na entrevista sociolingüística, Souza (2000a/b) propõe tomar, dentro do dispositivo teórico da $\mathrm{AD}$, a entrevista sociolingüística como 
uma modalidade material de enunciação, no interior da qual se pode observar uma interação. $\mathrm{O}$ autor analisa fenômenos convencionalmente ditos suprassegmentais (hesitações, gagueiras, pausas) que “(...) incidem sobre o processo do dizer e da constituição da subjetividade no exercício oral da linguagem" (Souza 2000a:02). Semelhantemente, propomo-nos a analisar a constituição da subjetividade na entrevista sociolingüística a partir de suas marcas materiais. Buscamos a interpretação "perdida" da qual então inferidor é marca lingüística, isto é, a interpretação que um falante faz ao dizer, mas que é apagada pela ilusão de ser a língua a fonte do sentido.

Extraímos os recortes discursivos analisados de trinta e seis ${ }^{3}$ entrevistas pertencentes ao Banco de Dados do Projeto VARSUL (Variação Lingüística Urbana da Região Sul), referentes à cidade de Florianópolis. ${ }^{4}$ Tais entrevistas foram realizadas de acordo com a metodologia da Teoria da Variação Lingüística (Labov 1972, 1994). Na entrevista sociolingüística, o entrevistador $(E)$ não está interessado no $o$ que é dito, mas no como. Busca o vernáculo, a “(...) enunciação e expressão de fatos, proposições, idéias ( o que), sem a preocupação de como enunciá-los. Trata-se, portanto, dos momentos em que o mínimo de atenção é prestado à língua, ao como da enunciação" (Tarallo 1985:19). Em sua busca do vernáculo, E procura deixar o falante $(F)$ à vontade: não revela o objetivo real da entrevista, dizendo, por exemplo, que usará o gravador apenas para poder lembrar melhor do que foi dito. Antes da realização da entrevista, $E$ obtém informações acerca dos interesses de $F$ em campos como família, religião, lazer, etc, para poder elaborar questões as quais $F$ terá mais facilidade em responder, permitindo uma maior "liberação" do vernáculo. Todos esses cuidados objetivam chegar a uma entrevista em que $F$ tenha a palavra durante a maior parte do tempo, sem preocupação com o como da fala.

\footnotetext{
3 Trata-se de trinta e seis entrevistas com informantes naturais de Florianópolis, distribuídos homogeneamente de acordo com os seguintes grupos de fatores sociais: sexo, idade (de 15 a 24 anos, de 25 a 49 anos e de 50 anos em diante) e escolaridade (primário, ginásio e colegial). Os entrevistadores são ou foram pesquisadores ligados ao Projeto VARSUL: professores e alunos do Curso de Graduação em Letras e do Curso de Pós-Graduação em Lingüística da UFSC.

4 O Projeto VARSUL, vinculado às universidades federais do Paraná, Santa Catarina e Rio Grande do Sul e à Pontifícia Universidade Católica do Rio Grande do Sul, constituiu um Banco de Dados através da documentação do português falado em áreas urbanas dos estados da região sul, colocando à disposição da comunidade científica um registro sistemático e atualizado da fala urbana regional.
} 
Observando o fenômeno do vernáculo através do dispositivo da $\mathrm{AD}$, podemos pensar as preocupações maiores de um falante relativamente ao $o$ que ou relativamente ao como da fala como refletindo posições de sujeito distintas a serem preenchidas - a construção de tais sujeitos é resultado de filiações em diferentes arquivos da memória discursiva. O como (de que forma material) aquilo que é passível de ser dito pode ser atualizado em determinado acontecimento discursivo também é regido pelas formações discursivas. É possível haver desde um sujeito mais preocupado com a organização lingüística dos sentidos a um sujeito que enfatiza os sentidos, o que resulta em diferentes mobilizações dos próprios sentidos. Dessa forma, o que se diz e o como se diz são inter-constitutivos e constitutivos do dizer.

A entrevista realizada no quadro da Teoria da Variação Lingüística é tida como o "local" onde se coletam os dados para o estudo de, por exemplo, variações fonológicas, morfológicas, sintáticas, etc. Costuma-se analisar somente a fala de $F$. Neste trabalho, a entrevista é tomada como uma interação em que $E$ e $F$ "negociam" as posições e sentidos. Não se trata, então, de um discurso de $E$ ou de $F$, mas de um discurso constituído em interação, envolvendo toda a multiplicidade de sujeitos e sentidos atualizados quando do acontecimento entrevista. "Neste sentido, a entrevista não é simplesmente um instrumento neutro de pesquisa ou um método, entre outros, de coleta de dados, uma caixa preta cujo funcionamento seria óbvio e fora de questão" (Mondada 1997:01).

\section{A interpretação}

Em nossa busca da interpretação "perdida", centramo-nos no uso de então como inferidor, com a hipótese de ser tal forma uma marca lingüística do processo de construção da subjetividade e da instanciação de sentidos na entrevista sociolingüística. Além de marcar inferência, então pode apontar para outros funcionamentos no discurso, tais como seqüenciação temporal, seqüenciação textual, introdução de efeito, retomada de informações, preenchimento de pausa (cf.: Tavares, 1999), os quais não constituirão o foco de nosso interesse no momento, embora sejam igualmente passíveis de análise dentro do dispositivo teórico da $\mathrm{AD}$.

Os trechos de entrevista que fornecemos como exemplo são recortes da superfície lingüística em que encontramos nosso objeto, as trinta e seis entrevistas do corpus de Florianópolis do Banco de Dados do Projeto VAR- 
SUL. Valendo-nos do dispositivo teórico da AD, analisamos as condições de produção do enunciado de inferência do qual então é marca material. Mais precisamente, averiguamos como o jogo de mobilização de sentidos instaurado pelo processo de inferência marcado lingüisticamente por então reflete-se sobre a interpelação do entrevistador em sujeito.

\subsection{Dos sentidos: um leva ao outro, um cala o outro}

Tomamos a entrevista sociolingüística como efeito de um dispositivo que movimenta múltiplos sentidos, atualizados por cada um dos interlocutores quando do momento do acontecimento, isto é, do momento da entrevista. Tais sentidos, visíveis na superfície lingüística, interrelacionamse, encontrando-se, equivocando-se, cada um deles mantendo também relação com sentidos outros, não atualizados, mas presentes como ausência necessária. "Há o primado do interdiscurso (a memória do dizer) de tal modo que os sentidos são sempre referidos a outros sentidos e é daí que eles tiram sua identidade" (Orlandi 1996:30-31). Ou seja, um sentido sempre constitui-se em relação a outros sentidos, presentes ou silenciados, numa trama de inter-relações não perceptíveis à primeira vista na superfície discursiva, posto que é apagada pelo efeito ideológico.

Objetivando ressaltar as inter-relações entre sentidos que perpassam o processo de inferência do qual cremos ser então inferidor uma marca material, analisamos comparativamente, a partir do recorte (1), os modos como a inferência é vista pela lógica e pela $\mathrm{AD}$ :

(1) E: Tu e tua esposa fazem planos pros seus filhos?

F: Ah, mas é claro, querida. Muito, muito plano. Pelo menos eu tenho três casas e o plano é esse: é dividir essas casas mais tarde pra eles, né? Tenho essa, tenho uma nos fundos e essa da praia. É.

E: Cada um vai ficar com uma?

F: [Cada uma] - o plano meu é cada um ficar com uma casa.

E: ENT $\tilde{A O}$ tu trabalhou bastante na vida pra ter três casa, né?

F: Não, não trabalhei muito, não. Esta é uma herança do meu pai, certo? E a outra de madeira é em terreno ainda da minha mãe, que está nos fundos. E a da praia, então, foi o fundo de garantia. Na época consegui tirar o fundo de garantia e comprei esta casa. (FLP 12, L 624)

\footnotetext{
5 O código que segue o trecho da entrevista a identifica. Por exemplo, (FLP 12, L 624) = informante de Florianópolis, entrevista número 12, linha 624.
} 
Inferir remete a uma capacidade cognitiva: a partir de evidências dadas (fatos, crenças, opiniões), inferimos certos sentidos, ou, em termos lógicos, chegamos a certas conclusões. Segundo a lógica, a inferência é um processo pelo qual se chega a uma proposição (a conclusão), afirmada na base de uma ou mais proposições (as premissas), que são o ponto de partida do processo. No entanto, o “(...) lógico não está interessado no processo de inferência, mas nas proposições que são o ponto inicial e final desse processo, assim como nas relações entre elas" (Copi 1978:21). O quadro a seguir ilustra a inferência segundo a lógica, tomando por base o recorte 1:

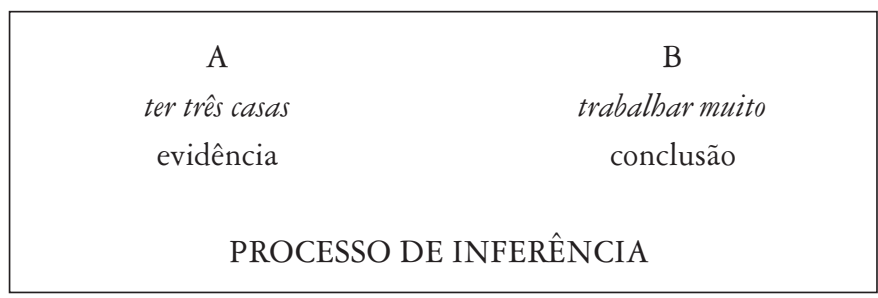

Quadro 1: Inferência segundo a lógica

O que interessa à lógica é o que está dado no discurso: a(s) premissa(s) (no caso do recorte (1), "ter três casas") e a conclusão (no recorte (1), "trabalhar muito na vida"), alcançada por meio do processo de inferência a partir da(s) premissa(s) de base. De acordo com a lógica, as premissas e conclusões presentes no discurso são funções derivadas (resultados) de um funcionamento discursivo, isto é, representam o sentido já lá. Diferentemente, para a $\mathrm{AD}$, inferir é efeito de um processo discursivo cujo funcionamento pode ser descrito pela relação entre o que se diz e os múltiplos dizeres correlacionados ao que se diz, os quais são dados na memória discursiva, ou interdiscurso. A inferência é vista de forma distinta da lógica, pois são levadas em conta as diversas possibilidades de sentido que se fazem presentes em cada formação discursiva. Ao empregar então em (1), $E$ está inferindo algo a partir da fala de $F$, algo que $F$ não disse, mas possível de ser depreendido do que disse. Trata-se de um sentido selecionado entre outros sentidos possíveis a partir da fala de $F$, todos inter-relacionáveis e mobilizáveis na memória do dizer.

Então inferidor aponta para um sentido que se relaciona a outros sentidos - tudo o que $E$ poderia ter dito e que foi recalcado ao ter sido privi- 
legiado o sentido expresso lingüisticamente por meio do ato de inferir. Melhor dizendo, as formações discursivas colocam como possíveis para um discurso diversos sentidos. O discurso é efeito da atualização de determinados sentidos e do conseqüente silenciamento de outros. Aquele sentido que está presente no enunciado (1), a inferência de fato feita, recalca os outros sentidos possíveis, que passam a existir no dizer como ausência constitutiva. A que outros sentidos se relaciona a inferência marcada por então em (1)? Do fato de $F$ ter três casas (premissa ${ }^{6}$ ), $E$ infere que ele trabalhou muito na vida. Dos sentidos possíveis, $E$ adota o do discurso da valorização do trabalho, o sentido A, mas poderia ter adotado também o discurso da corrupção (sentido B), o da herança (sentido C), o de ganhar na loteria (sentido D), etc. Enfim, o sentido de inferência pertinente a então em enunciados de inferência como o presente em (1) constitui-se entre os múltiplos sentidos dados como possibilidades para $E$.

Analisemos mais um recorte:

(2) E: A senhora tem filhos?

F: Tenho. Tenho cinco filhos.

E: É? Qual a idade deles?

F: Olha, eu tenho uma filha [com] - [ela vai fazer] - é, não, eu acho que ela fez trinta e oito anos. E tenho um filho com trinta e seis, tenho outra filha com trinta e quatro, outro filho com trinta. Eu já disse quatro, né? e tem o mais moço [com]-vai fazer vinte e nove anos.

E: ENTÃO a senhora já tem netos?

F: Ah, já. Tenho nove netos. Eu tenho um neto com doze anos. (FLP 15, L 076)

Em (2), após $F$ listar a idade dos filhos, $E$ infere que $F$ já tem netos, inferência possivelmente devida ao fato de que os filhos de $F$ têm idade para serem pais e mães. A inferência feita por $E$, de $F$ já ter netos, representa um dos sentidos possíveis na memória do dizer. Outros sentidos possíveis a partir da premissa " $F$ tem filhos adultos" poderiam ser "os filhos de $F$ trabalham", ou "os filhos de $F$ são formados numa universidade", ou

6 Cabe lembrar que os sentidos nunca estão evidentes num discurso, mas sempre constituindose, pois discurso é funcionamento. Assim, o termo "premissa" refere-se a um certo sentido presente na fala de $F$ que motiva a inferência feita por $E$. No entanto, não se trata de um sentido evidente, acabado, mas opaco, existindo em relação a outros sentidos disponíveis para $F$ na memória do dizer. 
ainda "os filhos de $F$ são casados e não moram mais com $F$ ", etc. Há muitos sentidos possíveis de serem atualizados no discurso de $E$. Com a opção por um dos sentidos disponíveis, o de que $F$ já deveria ter netos, $E$ é inserido em um discurso, por exemplo, da valorização da família. Se o sentido atualizado fosse outro, $E$ seria inserido em outro discurso.

Ressaltamos que, ao apontar a informação que cremos ter baseado a inferência feita por $E$, operamos nossa própria inferência, com o intuito de explicar como se dá o processo de inferência de $E$ : atribuímos a ele o ato de inferir de uma certa forma, relacionando o fato de $F$ ter filhos adultos (a premissa presente na fala de $F$ ), portanto, com idades para serem pais e mães, com o fato de $F$ ter netos. O processo que levou $E$ a imaginar que $F$ tem netos possivelmente transcorreu da forma descrita, mas, como não temos acesso direto a seu processo de inferência, apenas podemos inferir que $E$ tenha inferido um certo sentido a partir de um sentido presente na fala de $F$, no caso, a idade dos filhos de $F$. Também temos, portanto, de entrar no jogo das inter-relações de sentido instauradas pelo dito de $F{ }^{7}$

Então inferidor instancia uma espécie de anáfora, apontando para algo dito na fala de $F$, qual seja, a informação responsável por disparar a inferência na fala de $E$. Ou seja, marca lingüisticamente a existência de uma relação entre o que é dito por $E$ (por exemplo, em (2), "então a senhora já tem netos?") e outro sentido, aquele atualizado na fala de $F$ (em (2), a idade dos filhos), que se dá como referenciador do que é dito por $E$. O sentido referenciador pode ser recuperado lingüisticamente por $E$ em sua própria fala, o que ocorre na inferência em (1), "ENTÃO tu trabalhou bastante na vida pra ter três casa, né?”. Neste exemplo, a repetição por parte de $E$ do que disse $F$, "ter três casas", representa a reintrodução do sentido disparador de "trabalhou bastante na vida", sentido cuja existência era pressuposta pelo uso de então. Entretanto, na maioria dos recortes analisados, ${ }^{8}$ a não ser pela presença de então, o sentido referenciador é recalcado,

\footnotetext{
7 Empregamos o termo "recalque" para indicar o silenciamento de sentidos disponíveis na formação discursiva. Porém, como não podemos ter acesso direto ao processo de inferência de $E$, não nos é possível dizer para cada caso se a escolha foi automática e as outras possibilidades de sentido foram "desconhecidas", ou se $E$ pesou as possibilidades e privilegiou uma.

8 Analisamos 68 recortes com então inferidor. Destes, apenas o recorte número (1) apresenta a recuperação, junto à inferência, de seu sentido referenciador. Talvez isso tenha ocorrido porque a inferência não foi feita logo após o informante ter dito que tinha três casas.
} 
como ocorre em (2): $E$ não explicita o que, na fala de $F$, instaurou a busca e seleção de um sentido entre vários dados como possíveis por certa formação discursiva (tudo o que se pode dizer relativamente a ter filhos, por exemplo), apenas indicando, pelo uso de então, que algo dito por $F$ permitiu a $E$ inferir certo sentido. Temos, portanto, então não apenas como marca material do jogo de mobilização de sentidos instaurado pelo processo de inferência, mas também como índice de que um sentido está recalcado na fala de $E$, o sentido instaurador da inferência, e, portanto, constitutivo da própria inferência.

Então inferidor é uma das pistas lingüísticas que nos permite perceber que $E$ está inferindo a partir de algo que $F$ mencionou, mas não é a única: há também a entonação interrogativa que sempre acompanha a inferência marcada por então. No decorrer do processo de inferência, um sentido na fala de $F$ induz $E$ a buscar um outro sentido, interrelacionado ao primeiro, nos arquivos da memória discursiva. Como vários sentidos são dados como possibilidades, $E$ é tomado num lugar de incerteza quanto a qual deles irá assumir. Temos, assim, como marca lingüística da posição de incerteza na qual foi lançado $E$ a sentença interrogativa com então, que solicita confirmação acerca do sentido selecionado por $E$ para ser atualizado. Como conseqüência, no turno seguinte, $F$ confirma ou refuta a inferência feita por $E$. Portanto, no caso da inferência com então, os sentidos outros ou ao menos a possibilidade de sentidos outros não é silenciada totalmente. Há uma espécie de recalque latente, pois a interrogação, marca da incerteza, aponta para a existência de outras possibilidades de sentidos - sentidos latentes, passíveis de serem atualizados. Por exemplo, após refutar o sentido instanciado por $E$, em (1) - "Não, não trabalhei muito, não." - $F$ instancia outro sentido, o da herança - "Esta é uma herança do meu pai, certo?"-, uma possibilidade presente nos arquivos acerca da posse de bens materiais.

Se não houver entonação interrogativa, teremos outro funcionamento de então, o qual podemos denominar "conclusivo". Então conclusivo marca um lugar de certeza: $E$ julga que o que concluiu é verdadeiro, não necessitando da confirmação de $F$ para instaurar o sentido selecionado, o que se faz necessário na inferência denotada por então inferidor. Dessa forma, então conclusivo congela a posição de $E$, fechando o jogo discursivo para as diversas possibilidades de sentidos que poderiam advir se $F$ fosse interpelado a assumir determinada posição através de uma inferência e seu pedido 
de confirmação. Ou seja, há um forte recalque de outros sentidos possíveis. Veja-se a seguir:

(3) E: Datilografia?

F: Isso. A minha parte é dar a ficha do pessoal. Muitas vezes fico até na cozinha, às vezes, quando faltam. É.

E: Tem cozinha lá?

F: Tem.

E: Aí vocês almoçam lá? Todo mundo almoça lá? Alguém fica nesse horário?

F: [Não]- não, almoça ali na Base, o que? [Uns] - umas quarenta e duas pessoas.

E: ENTÃO tu gostas, vais pra cozinha. Tem cozinheiro fixo?

F: Não tem. Isso, não tem. Bom, fixo tem. (FLP 18, L 607)

Em (3), o fato de $F$ ir para a cozinha porque gosta é dado por $E$ como evidente, impossibilitando a entrada de $F$ na posição discursiva instaurada por então conclusivo, tanto que, na seqüência, silenciado, $F$ não confirma ou refuta seu gosto pela cozinha. Quando é instanciada uma necessidade de confirmação por parte de $F$ (caso de todos os recortes analisados em que aparece então inferidor), surge um espaço para outros sentidos fazerem-se presentes no discurso. Então inferidor desvela a possibilidade de múltiplos sentidos. Diferentemente, então conclusivo marca o outro como ausência, fechando o jogo de mobilização de sentidos.

$\mathrm{O}$ quadro abaixo ilustra a visão da inferência da AD. Há sempre uma pluralidade de sentidos em jogo, armazenados na memória do dizer como decorrência da experiência humana ao longo do tempo, os quais podem ser assumidos pelos falantes. No caso da inferência sob investigação, aquilo que foi dito por $F$ leva $E$ a buscar um certo sentido, uma certa relação em seus arquivos de memória - sentido que pode configurar um percurso a ser seguido no/para o desenrolar da entrevista, isto é, sentido passível de disparar novos sentidos a serem atualizados materialmente por $E$ e $F$ e, ao mesmo tempo, passível de levar ao recalque de outros sentidos - um sentido leva ao outro, um sentido cala o outro. 


\begin{tabular}{|cc|}
\hline \multicolumn{2}{|c|}{$\begin{array}{c}\text { interdiscurso } \\
\text { B C D E F G }{ }^{9} \ldots\end{array}$} \\
A & B \\
ter três casas & posição discursiva muito \\
posição discursiva & \\
& \\
PROCESSO DE INFERÊNCIA &
\end{tabular}

Quadro 2: Inferência segundo a AD

\section{Vejam-se:}

(4) F: Era tudo assim: troncos assim de madeira, né? Então os carros passavam por ali, faziam um barulho danado em cima daqueles troncos de madeira. Porque não tinha asfalto, não tinha nada, paralelepípedo, nada, era tronco de madeira. Então às vezes-

E: Meu Deus! Dava pra ver o mar, ENTÃO?

F: Dava, dava pra ver o mar. E tinha onde tem a parte onde passavam os carros, e tinha um lado que era um acostamento $[<\mathrm{pa}->]$ - que passava o pedreste, né? (FLP 18, L 222)

(5) E: E que partes do jornal a senhora mais gosta?

F: Gosto muito de ler a parte policial, (hes) notícias, né? política- (espirro)

E: Pode continuar.

F: É, o que eu leio mesmo é essas folhas, assim (inint).

E: Essas partes?

F: Essas partes assim.

E: Ãh, hã, a senhora gosta de política, ENT $\tilde{A O}$ ?

F: Gosto. Ah, gosto. [Não, gosto de]- não é que eu gosto de política, eu gosto, assim, de ver [o]-como é que está a política, né? essas coisas aí que a gente está escutando todo dia, aí. (FLP 15, L 123)

9 B, C, D, F, G representam $\mathrm{N}$ sentidos possíveis (em termos lógicos, conclusões) de serem derivados do sentido presente na fala de $F$ (a premissa que motivou o processo de inferência). Ao ser tomado por um dos sentidos, $E$ é colocado em certa posição discursiva. Se o sentido assumido fosse outro (C, D, E...), a posição em que $E$ se colocaria seria outra. 
(6) F: Então era assim: [segunda $<$ fe- $>$ ]- (inint) sábado, domingo e terça era no Doze, (hes) sábado, segunda e terça era no Lira.

E: ENTÃO eram mais entrosados o Lira e o Doze?

F: Era, era. E aí quando terminava o baile na terça-feira, na Quarta-feira de Cinzas, os clubes se encontravam na praça, e volteava-se a praça, os clubes, os restantes dos foliões, né? Então a gente [subia pra o] - ia pela praça (...) (FLP 24, L 382)

Em (4), $F$ descreve a ponte Hercílio Luz ${ }^{10}$, sendo interrompido por $E$, que pede a confirmação de uma inferência: a de que seria possível ver o mar através da ponte (como não havia asfalto ou paralelepípedo, apenas troncos de madeira). F confirma ("Dava, dava pra ver o mar"). O segundo então, o da fala de $E$, desloca o primeiro, presente na fala de $F$ ("Então às vezes..."). Embora não saibamos para onde o primeiro então apontaria, possivelmente não conduziria ao mesmo jogo de sentidos que é instaurado pelo segundo então, o qual leva a continuação da descrição da ponte ${ }^{11}$. Ou seja, o emprego do inferidor influi no vir-a-ser da entrevista, instaurando sentidos passíveis de modificar os rumos tomados pela fala de $F$. Assim é que, em (4), E mobiliza outra direção com o seu então inferidor, e $F$ "aceita" o deslocamento discursivo proposto por $E$, continuando a descrever a ponte ("E tinha onde tem a parte onde passavam os carros..."). Em (5), ocorre um movimento semelhante: a inferência feita por $E$ de que $F$ gosta de política induz $F$ a deslocar sua fala acerca de jornais para questões envolvendo o tema "política". A materialização lingüística de um sentido não insere somente $E$ num discurso, mas também $F$. Destarte, então inferidor marca a instanciação de rumos que podem ser seguidos para fazer avançar a entrevista, isto é, o sentido introduzido na fala de $E$ como efeito do processo de inferência marcado por então aponta para sentidos passíveis de vir à tona no/para o decorrer da entrevista.

Como já havíamos mencionado, então é índice material do jogo de mobilização de sentidos instaurado pelo processo de inferência, ao que se soma o indiciamento de que algo está recalcado na fala de $E$, qual seja, o sentido instaurador da inferência. Consideramos esse apontamento ao recalque de algo dito anteriormente no discurso como anáfora. Parece que então marca ainda uma catáfora, um vir a ser para o discurso, uma vez que

10 A ponte Hercílio Luz fica em Florianópolis, SC.

11 A impressão deixada pela sentença interrompida por $E$ é de que $F$ estava concluindo a descrição da ponte que vinha fazendo, para iniciar talvez uma narrativa envolvendo a ponte. 
o sentido atualizado através da inferência marcada por então aponta para outros sentidos, isto é, trata-se de um sentido que aponta para novos rumos a serem seguidos na/para a constituição da entrevista, mobilizando arquivos de memória distintos daqueles que vinham sendo mobilizados até o momento. Ressalvamos, porém, que $F$ pode não aceitar o rumo proposto através da inferência, como exemplifica o recorte (6), em que $F$ é introduzido no discurso do entrosamento entre os clubes apenas para confirmar a inferência feita por $E$, voltando imediatamente para o rumo que vinha tomando antes da inferência: a narração do que acontecia durante o período do carnaval. De qualquer forma, o sentido tornado material por meio da inferência coloca $F$ na posição de ter de ao menos confirmá-lo ou refutá-lo, desviando-se das inter-relações de sentido que vinha traçando.

\subsection{Dos sujeitos: subjetividade no quadro teórico da sociolingüistica variacionista}

Até agora, centramo-nos mais detidamente na questão da mobilização e do recalque de sentidos instaurados pelo processo de inferência marcado lingüisticamente por então. Entretanto, já ao abordar os sentidos, abordamos também a questão das posições ocupadas pelos sujeitos do acontecimento discursivo em foco, a entrevista sociolingüística. Por exemplo, dissemos que, como vários sentidos são dados como possibilidades, $E$ é tomado num lugar de incerteza quanto a qual deles irá assumir; dissemos também que a materialização lingüística de um sentido insere $E$ num determinado discurso, em detrimento de outros. Ou seja, quando investigamos o jogo entre sentidos desencadeado pelo processo de inferência, investigamos também a interpelação do entrevistador em sujeito. A análise do sentido não é desvinculada da análise do sujeito: um integra a constituição do outro, em uma inter-relação que culmina com a construção do discurso. No caso específico aqui considerado, o da entrevista sociolingüística, o processo de inferência incide sobre a constituição da subjetividade de $E$, interpelando-o como sujeito no momento da interlocução. Sob que condições isso acontece?

A inferência cuja marca é então aparece, nas entrevistas analisadas, na fala do sujeito entrevistador. Essa materialização de então apenas na fala de $E$ não é um acontecimento desvinculado da historicidade. A análise da constituição do sujeito do dizer e daquilo que é dito por ele deve levar em 
conta a história de constituição desse sujeito, pois "não é o sujeito (locutor) que se apropria da linguagem, mas há uma forma social de apropriação da linguagem em que está refletida a noção de sujeito, isto é, sua interpelação feita pela ideologia" (Orlandi 1986:47) As formações ideológicas, constituídas ao longo da experiência humana com o mundo, especificam para as formações discursivas os padrões de ver e dizer dentro de domínios quaisquer da vida humana. A partir de tais padrões, as formações discursivas interpelam o indivíduo em sujeito, isto é, colocam-no em certa posição, da qual produz um discurso conseqüentemente determinado ideologicamente - como ele próprio.

As formações discursivas autorizam os sentidos que são atualizados a cada discurso e fornecem aos sujeitos, através das formações imaginárias, certas imagens de si e do outro, as quais são parte constituinte das posições a serem ocupadas pelos sujeitos. Tais posições, assim como os sentidos, são construídas historicamente pelo contexto ideológico-institucional em que está inserido o sujeito. A instituição a que se relacionam de forma constitutiva os enunciados que analisamos é a da pesquisa no quadro das ciências humanas, em particular, da teoria sociolingüística laboviana. ${ }^{12}$ A postura de $E$ em relação a si, ao seu locutor, e em relação aos sentidos não é desvinculada de uma prática discursiva que determina certa formação discursiva - uma formação discursiva que rege sujeitos e sentidos em uma entrevista sociolingüística. Ou seja, a posição sujeito do entrevistador (do cientista da linguagem dentro de uma teoria, a sociolingüística variacionista) é derivada de uma formação ideológica constituída historicamente: padrões de ver e dizer o mundo (e a si mesmo) dentro de uma entrevista. $E$ não possui uma subjetividade própria, mas sim a que lhe é dada via formação imaginária ao assumir o papel de entrevistador. A voz que fala, portanto, não é a de $E$, pessoa física, mas a do papel-sujeito entrevistador ligado à instituição, ao quadro teórico-metodológico em que $E$ está inserido.

De acordo com o previsto metodologicamente para uma entrevista que servirá à pesquisa sociolingüística variacionista, o entrevistador detém

\footnotetext{
12 Ao dizermos que os enunciados que analisamos relacionam-se de forma constitutiva a certo campo teórico, estamos considerando tal campo não como fechado, apenas fornecendo o que já existe em si. As formações ligadas a qualquer prática nunca se fecham. O já constituído atua sobre cada discurso novo, mas há a contraparte: cada acontecimento discursivo traz reflexos sobre a prática em que se insere, modificando-a.
} 
o controle da interlocução, determinando os temas e mudanças de temas através de perguntas dirigidas ao informante. A entrevista sociolingüística é marcadamente assimétrica, uma vez que $E$ ocupa a posição de controle do acontecimento, a posição daquele que quer saber, cabendo a $F$ a posição daquele que deve fornecer as informações que seu interlocutor precisa/ solicita. $E$ fala de uma posição voltada para o estímulo à fluição da entrevista, assujeitado por um papel cujo fim é levar o interlocutor, $F$, a falar, pois é a fala dele que será o local de coleta de dados de variação lingüística. Haver grandes períodos de silêncio por parte de $F$ resultaria em uma entrevista imprópria para os fins que a instauram, por isso $F$ deve deter a palavra durante a maior parte da entrevista, vetando-se a ele o silêncio. ${ }^{13}$

Nesse acontecimento de natureza assimétrica que é a entrevista sociolingüística, as táticas de levar a conversação à sua continuidade estão fortemente ligadas a $E$, interpelado na posição de guia do dizer. Pensamos então inferidor como uma marca material dessa posição "entrevistador". ${ }^{14} E$ é assujeitado pela necessidade de inferir. O processo de inferir é constitutivo do papel sujeito entrevistador, uma vez mobiliza sentidos que representam novos rumos a serem seguidos no/para o decorrer da entrevista: a atualização de certo sentido assujeita $F$ de um certo modo ( $F$ terá de, ao menos, confirmar ou recusar o sentido inferido por $E$ ), influindo no vir-a-ser da entrevista. Ao intervir na fala de $F$, inferindo a partir do que $F$ disse e, ao mesmo tempo, questionando a inferência que fez (a inferência é acompanhada da interrogação), $E$ aponta para sentidos diferentes, sugerindo incursões possíveis pelo interdiscurso.

13 A maioria das entrevistas por nós analisadas tem sessenta minutos de duração; a mais curta, quarenta e cinco.

14 Foucault (1995) aponta que o sujeito do enunciado é uma função determinada, mas não obrigatoriamente a mesma de um enunciado a outro, pois trata-se de uma função vazia, que pode ser exercida por indivíduos até certo ponto indiferentes quando formulam o enunciado; além do que um único e mesmo indivíduo pode ocupar alternadamente, em uma série de enunciados, posições diferentes e assumir o papel de sujeitos diferentes. No caso do emprego de então inferidor na entrevista sociolingüística, seu sujeito enunciador não é um indivíduo específico, mas aquele que fala da posição sujeito entrevistador. Tal posição não é fechada, pré-determinada, pois o indivíduo pode assumir vários papéis, que se somam ao de entrevistador, a cada entrevista que faz e mesmo durante uma mesma entrevista. Por exemplo, será jovem frente a um informante de mais idade e será um adulto frente a um informante adolescente, o que representa o assujeitamento a diferentes papéis e diferentes modos de dizer. 
Então inferidor marca um lugar de deslocamento de sentidos - do sentido introduzido por $F$ que motiva a inferência de $E$, deste sentido inferido por $E$ aos que a partir dele seguirão. Esse deslocamento culmina com a construção do discurso entrevista. $E$, interpelado na posição de pesquisador, é tornado agente materializador da atualização e do deslocamento de sentidos. Entretanto, o uso do inferidor também convoca $F$, mediante as intervenções de $E$, em múltiplas possibilidades de tornar-se sujeito. F é levado a assumir posição frente ao sentido introduzido por $E$ a partir de sua (de $F$ ) fala, o que conduz a interação a sua continuidade, calando-se o silêncio tão temido em uma entrevista sociolingüística.

\section{Considerações finais}

Analisamos as inter-relações entre o jogo de mobilização e recalque de sentidos instaurado pelo processo de inferência, a posição sujeito entrevistador e uma forma material, então inferidor, marca lingüística das interrelações investigadas e, portanto, uma de suas partes constituintes. As inter-relações em questão, apagadas no discurso pela ilusão de ser a língua a fonte do sentido, são postas em funcionamento pelos desígnios das formações imaginárias, discursivas e ideológicas, culminando com a constituição da entrevista sociolingüística. Assim, não pensamos então inferidor como evidente, concreto, como uma marca de uma função, a inferência, dada como pronta no discurso, mas antes uma marca de um funcionamento, de um processo de constituição do dizer impossível de ser desvinculado de suas condições de produção, de seu processo histórico de constituição.

Abordamos então inferidor como marca de um lugar de instanciação de sentidos, de recalque de sentidos, de questionamento de sentidos, de sentidos latentes, de apontamento anafórico e catafórico de sentidos para a continuidade da entrevista, para o inserir-se em novos vir-a-ser do discurso, enfim, marca do lugar constituído historicamente como o lugar do entrevistador. Portanto, marca da atuação da historicidade via formações discursivas sobre a instanciação de sentidos e conseqüentemente sujeitos (ou vice-versa - sujeitos e sentidos existem em inter-relação constitutiva), processo que incide na constituição da entrevista sociolingüística enquanto espaço de manifestação da multiplicidade de sentidos e de sujeitos vinculados à prática dentro do quadro teórico da sociolingüística variacionista. 
E-mail: aliceflp@hotmail.com Recebido em setembro de 2002 Aprovado em outubro de 2003

\section{REFERÊNCIAS BibLIOGRÁFICAS}

CopI, Irving M. 1981. Introdução à Lógica. $2^{\mathrm{a}}$ ed. São Paulo: Mestre Jou. Foucault, Michael. 1995. Arqueologia do Saber. $4^{\mathrm{a}}$ ed. Rio de Janeiro: Forense Universitária.

Labov, Willian. 1972. Sociolinguistic Patterns. Philadelphia: University of Pennsylvania Press.

. 1994. Principles of Linguistic Change: Internal Factors. Oxford: Blackwell.

Maingueneau, Dominique. 1993. Novas Tendências em Análise do Discurso. Campinas, São Paulo: Pontes: Ed. da Universidade Estadual de Campinas.

MondADA, Lorenza. 1997. L'Entretien comme Événement Interactionnel. Approche Linguistique et Conversationnelle. Mônica Zoppi-Fontana (trad.). Rua 3, LABEUR.

Orland, Eni Puccinelli. 1986. A Análise do Discurso: Algumas Observações. D.E.L.T.A. 2/1: 105-126. . 1996. Interpretação. Rio de Janeiro: Vozes.

PÊCHeux, Michel. 1988. Semântica e Discurso - uma Crítica à Afirmaçãa do Óbvio. Campinas, Ed. da UNICAMP.

SouzA, Pedro de. 2000a. Os Suprasegmentos como Índices da Subjetivação na Enunciação Oral. Revista da ANPOLL 8. S.P: Humanitas/FFLCH/ USP.

. 2000b. Jogando Conversa Fora: a Gênese do Sujeito Falante em Entrevista Sociolingüística. Linguas e Instrumentos Lingüísticos 5. Campinas, São Paulo: Pontes Editores e Projeto História das Idéias Lingüísticas no Brasil.

Tarallo, Fernando. 1985. A Pesquisa Sociolingüústica. São Paulo: Ática.

Tavares, Maria Alice. 1999. Um Estudo Variacionista de aí, daí, então e e como Conectores Seqüenciadores Retroativo-propulsores na Fala de Florianópolis. Dissertação de mestrado. Florianópolis, UFSC. Impresso. 